\title{
Engineering Education through a Flipped Classroom Model
}

\author{
David Wang and Adam Gomes \\ University of Waterloo, Waterloo, ON, N2L3G1 \\ dwang@uwaterloo.ca adgomes@uwaterloo.ca
}

\begin{abstract}
A flipped classroom model is used to teach a 4th year multi-variable control systems course. This course is a technical elective and is not in the core curriculum. The capstone project is to model and control a nonlinear robot in simulation. The students are interdisciplinary Engineering students (Mechanical, Mechatronics, Computer and Electrical). Building upon accepted best practices for flipped classrooms, several additional enhancements are applied and evaluated. The results of student surveys as well as a comparison of the results of student performance in the capstone project between traditional and flipped lecturing techniques are presented. It is believed that the enhancements that were implemented can aid in future flipped classroom initiatives.
\end{abstract}

Keywords: Flipped Classroom, Active Learning, Capstone Project, Student Feedback, Engineering Education

\section{INTRODUCTION}

In response to poor student performance in a $4^{\text {th }}$ year advanced multivariable control systems course using traditional lecturing methods, a flipped classroom is implemented. The topics covered in this course include a review of linear algebra, linearization, state space equations, observability, controllability, state feedback, state estimators, linear quadratic regulators and Kalman filters. The topics covered were identical in both offerings. The course is open to all engineering students and is an elective course.

In addition to best practices suggested by previous researchers, several additional enhancements are implemented and evaluated in this paper. The evaluation of the flipped class is done through student surveys. One identical component of both offerings is the capstone project. Thus, it is possible to compare student learning between these two styles of content delivery by examining the student outcomes of the capstone project. The flipped classroom is demonstrated in this paper to result in deeper learning and that the proposed enhancements are perceived to be beneficial by the students.

\section{BACKGROUND}

Flipped classrooms have a recent focus of effective pedagogy. The flipped classroom is described by Bishop and Verleger [1] as requiring out-of-class video content and mandatory in-class interactive activities. In the 24 studies surveyed in their paper, they noted that successful implementations also used class quizzes and short videos. The authors also recommend that more clear descriptions of the interactive activities designed for these courses need to be reported in the literature. Herreid and Schiller [2] noted that, out of 15000 STEM teachers, only 200 tried a flipped classroom. Pitfalls were identified as initial student resistance and the lack of available online videos, which requires instructors to create their own video content. In Mason, Shuman and Cook [3], a similar upper year engineering course to the one in this paper was successfully implemented, with positive student success and satisfaction. The successful implementations described above are built upon to deliver the flipped content in this paper.

\section{PREVIOUS TRADITIONAL CLASS}

The previous offering of this course course was done in a traditional manner, where there were 3 hours of lectures as well as an hour tutorial every week. There were 66 engineering students (44 Mechatronics, 6 Mechanical, 13 Electrical, 2 Computer and 1 Systems Design). The capstone project is judged to be most relevant to the Mechatronics and Mechanical engineering students, who made up $76 \%$ of the students.

The students were given partial PowerPoints in PDF format. The students were instructed to follow the lectures and fill in the missing material. This was to encourage the students to be actively engaged in the lecture. The attendance, however, was approximately 50\% throughout the term at the lectures. It was found that many students relied on photocopying notes from their classmates.

The project involved designing a controller to move a robotic arm (see Figure 1) from A to B to C to D and back to A. At each point, the robot must settle to within $2 \mathrm{~mm}$ for .5 seconds before moving to the next point. The students were given the nonlinear dynamic equations and 
had to linearize the equations to do their linear controller design. They had full flexibility to choose the physical parameters of the robot (e.g. mass links and lengths), with some constraints on the total mass. They had to ensure the end of the robot did not make contact with the boundaries. The controllers only have access to the joint angles. The simulations were also done with the joint measurements corrupted with noise. The students were ranked according to the speed with which they accomplished the task as well as the energy used. The best performances would be given up to $2 \%$ bonus marks which was applied to their final mark. The students were given hints on how to linearize the system and how to change the linear controllers from one operating point to the next.

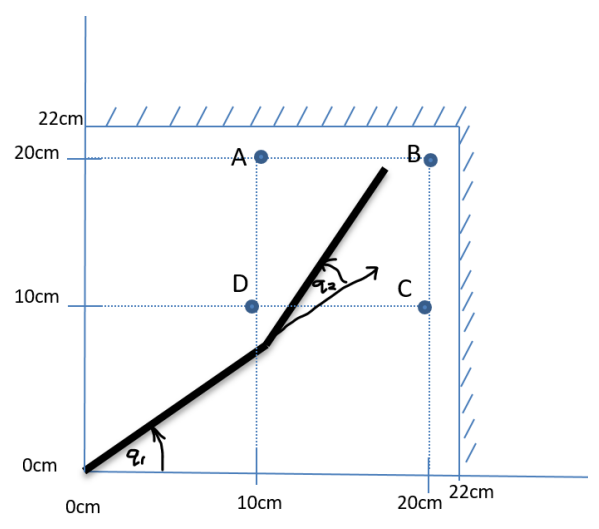

Figure 1: Robot arm

The capstone project was very poorly done. The students were divided randomly into groups of three, resulting in 22 groups. Only $45 \%$ of the groups completed the project objectives with no noise at the joint angles. When noise was added to the joint angles in the simulation, none of the groups succeeded in meeting the goals of the project.

Given the poor performance on the capstone project and the poor attendance issues, the question arose as to whether the students really understood and could apply the course material. As well, whether the students could use the software tool (MATLAB) was a matter of concern.

\section{FLIPPED IMPLEMENTATION}

Due to the issues raised, a fully flipped classroom is implemented in this study. This offering consists of 32 engineering students (15 Mechatronics, 6 Mechanical, 7 Electrical, 2 Computer, 1 Systems Design and 1 exchange student). The project is more familiar to the Mechatronics and Mechanical Engineering students who make up only $66 \%$ of the class.
An email was sent to the students prior to the start of the course, explaining that the lectures would be delivered in a flipped format and that every lecture had to be viewed by the student prior to the in-class session. Attendance was extremely important as every class had either a quiz based on the video lecture or had a MATLAB deliverable based on the in-class assignment. Immediately, 8 out of 38 students dropped the course although 2 students eventually joined the course. It is suspected that the flipped format caused this sudden attrition.

In all, 25 video lectures were recorded, with an average length of 30 minutes 12 seconds and with a standard deviation of 9 minutes. The shortest is 12 minutes long and the longest is 51 minutes long. This is significantly longer than previously reported times of 20 minutes [5] that students perceive as the ideal length.

The videos follow the format of the traditional content delivery in that the students are given partially completed notes in PDF format. They are instructed to follow along with the video and fill in the blank portions along with the instructor. This is one of the primary enhancements from previous studies. This is used to force the student to be an active participant rather than just a passive viewer, which is argued to increase understanding [4]. This is used to justify the longer video times as it is anticipated that notetaking would engage the student for a longer period of time. To emphasize this practice, the paper in [4] was made available to the students. In addition, a quiz given near the beginning of the term requested a repetition of the last part of the current video lecture. The students recognized that just watching the video did not allow them to recall information as much as writing them down by hand.

The online videos are primarily created using a Microsoft Surface Pro and One Note to do the annotations. A Blue Yeti microphone is used to improve the audio and screen capture is accomplished using Apowersoft Screen Recorder Pro which allowed the files to be captured in a compressed format for easy editing. The lectures normally have a few minutes at the start with a webcam recording of the instructor to give an overview of the lecture. This also creates a connection with the instructor. The lectures pay particular attention to exaggerating instructor voice inflections (to decrease boredom for the listener) and the use of the annotation software highlighter to "point" to the parts of the screen being discussed (as the listener could no longer take cues from the instructor as to which part of the notes were being referred to).

A discussion forum is used to provide quick feedback to the students on the video lectures. The platform piazza.com is used. There is an average response time of 55 minutes to questions about the course material, including those questions that arose in the middle of the night. Both Teaching Assistants and instructor respond to questions although there was also peer mentoring that occurs. 
A significant effort is made towards providing in-class activities for the students. We believe that excellent quality Teaching Assistants are essential to this part of course delivery. We aim for a Teaching Assistant to Student ratio of 1 to 10 . This appears to be the minimum to support the classroom activities. Thus, this is a human resource issue that should be addressed in any attempt to flip a classroom.

The students are randomly assigned into groups of 2 for the class deliverables and for the capstone project. Two of the groups did not work out and split into 4 individual submissions. This created 18 group evaluations for this course offering.

In order to ensure attendance, either a short quiz on the video lecture is conducted at the start of lecture or a MATLAB script file is submitted as a class deliverable as part of the day's in-class activity. Over the term, these deliverables make up $20 \%$ of the final mark. Regardless of the class deliverable, the time spent during the three weekly one hour lecture time slots is spent on solving problems, primarily with MATLAB. The class deliverable is carefully designed so that the vast majority of the students can complete them during the one hour time slot. Some of the more capable students complete very quickly so there is a second problem that is given to the students that is more difficult should they complete that question, they are encouraged to use the theory and techniques learned in class on their capstone project. Virtually all the students stay to the very end of the time period and often have to be asked to vacate the room for the next instructor.

Creating a final exam is a challenge. Because the focus on the class is on design using the MATLAB platform, it is desirable to create a final exam replicating similar problems. A special computer laboratory is booked where it is possible to shut off all internet access. The students have a combination of paper questions and MATLAB scripts to deliver. After the exam, there is a procedure implemented to allow collection of the scripts off of the individual computers. Contingency plans for computer problems and to provide access to those with accessibility requests also have to be considered.

\section{RESULTS OF FLIPPING THE CLASS}

There are many benefits that are immediately obvious after flipping this course. First, attendance was over $90 \%$ throughout the entire term. There were 2 out of the 32 students that were consistently absent from class. These 2 students were the only to fail the course. In the tutorials, which exclusively focuses on the capstone project, there was approximately $70 \%$ attendance.

Similar to findings in [1], the course material is completed much quicker (10 weeks as opposed to 12 weeks) and a few more topics are covered in greater detail (eg. Kalman filter for noise in the sensors).
The capstone project results are much improved from the traditional offering. The groups are smaller (two members on average) than the previous offering. This resulted in 18 groups. In the flipped offering, 11 groups (61\%) completed the project specifications without sensor noise at the joints. This is greatly improved from the $45 \%$ the previous year. Some groups failed because they did not stay at each point for the specified .5 seconds. If we were to relax this one specification, then 16 groups completed with all the other specifications met, which was $89 \%$ of the groups. If we were to similarly relax the specifications the previous year, there would have been no additional groups that would have been successful. When sensor noise was added to the simulation, 9 groups $(50 \%)$ successfully met all the specification. This is a great improvement over the previous year when no groups were able to accomplish this task. Overall, the improvement in the performance on the capstone project was remarkable. This confirms, as shown in previous studies, that deeper learning happens for a flipped classroom.

Two questionnaires are also completed by the students at the end of the course. The first set of questionnaires deal with the student's perception of the flipped classroom. There were 30 responses out of 32 total students. The first few questions discuss the online videos.

The students are asked whether they enjoy watching the online videos. The results are summarized in Table 1. The responses leaned solidly toward agreement.

Table 1

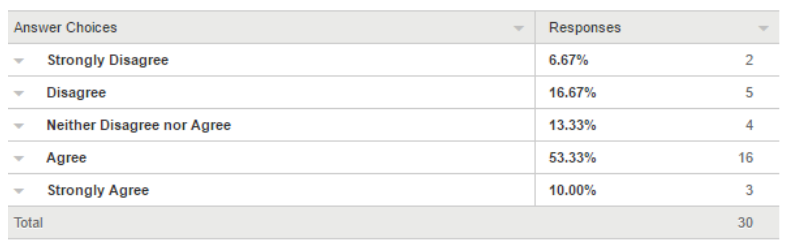

The students are then asked about the length of the video. Although the length is longer than suggested in the literature, it was believed that asking the students to annotate their own notes allowed lectures to be longer. The responses in Table 2 indicate that there is no issue with the longer lengths.

\section{Table 2}

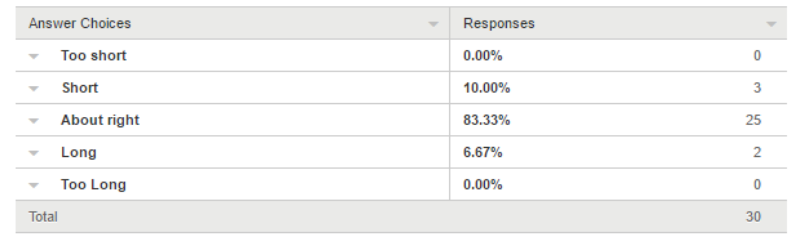

Although students were strongly encouraged to annotate their own notes, it is possible that the students did not take 
this route. The students are asked how often they took notes by hand when watching the videos. The results in Table 3 indicate that the students did take our advice regarding this.

\section{Table 3}

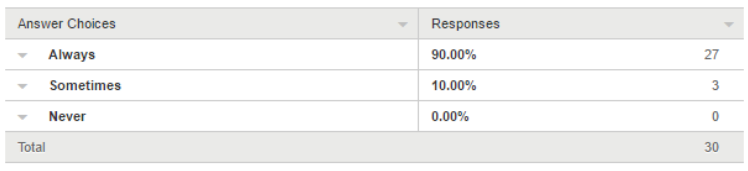

The students are then asked questions regarding the difficulty level of the class deliverables (MATLAB script files). With regard to the class-time activities, these would deal with the simple first question and not the more difficult second question asked. Table 4 indicates that the students found even the easier questions reasonably challenging.

\section{Table 4}

\begin{tabular}{l|lr}
\hline Answer Choices & Responses & \\
\hline Easy & $6.67 \%$ & 2 \\
\hline Somewhat easy & $3.33 \%$ & 1 \\
\hline Just right & $53.33 \%$ & 16 \\
\hline Somewhat hard & $23.33 \%$ & 7 \\
\hline Hard & $13.33 \%$ & 4 \\
\hline Very Hard & $0.00 \%$ & 0 \\
\hline Total & & 30 \\
\hline
\end{tabular}

Given that the capstone project is referred to throughout the course and is a significant amount of the workload, it is important to ascertain whether the project helps in deeper learning. The question is asked as to whether the project helps in understanding how to apply the course material. The responses in Table 5 indicate that the course project is essential to course delivery.

\section{Table 5}

\begin{tabular}{l|lc}
\hline Answer Choices & Responses & \\
\hline$-\quad$ Disagree & $0.00 \%$ & 0 \\
\hline$-\quad$ Somewhat disagree & $3.33 \%$ & 1 \\
\hline Neither Disagree nor Agree & $3.33 \%$ & 1 \\
\hline$-\quad$ Somewhat Agree & $46.67 \%$ & 14 \\
\hline$\quad$ Agree & $46.67 \%$ & 14 \\
\hline Total & & 30 \\
\hline
\end{tabular}

As indicated earlier, the students were initially woefully ill-prepared for working with MATLAB. However, the flipped format allows the Teaching Assistants and instructor to see where the difficulties lie and to help the students with these software tools. The response to the question as to whether the student feel confident in their abilities to use MATLAB after the course is over is presented in Table 6 and indicates improvement.
Table 6

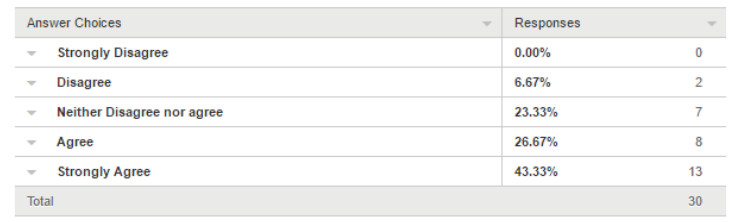

The students are also asked about the total amount of time, including the in-class portion and tutorials, spent on this course. Although 1 student spent less than 5 hours per week on the course and 5 students spent more than 9 hours per week on the course, the rest of the students surveyed (81\%) spent between 5 to 9 hours in total on the course, which is judged to be a reasonable workload for the student. This is confirmed by the students in that $52 \%$ of the students felt that this course is the same workload as their other courses whereas $14 \%$ felt it is less work and $34 \%$ felt it is more than their other courses.

At the end of the term, the instructor conducted two traditional lectures to give students a reference point to compare the two pedagogies. There are 26 respondents to these survey questions.

A first question asks the student's perception of their ability to deal with new nonlinear problems, including linearization which was not understood well. This is particularly important given that the threshold concept of linearization was uncovered in the flipped setting as being very poorly understood. Table 7 shows that the students feel quite prepared to encounter new problems.

\section{Table 7}

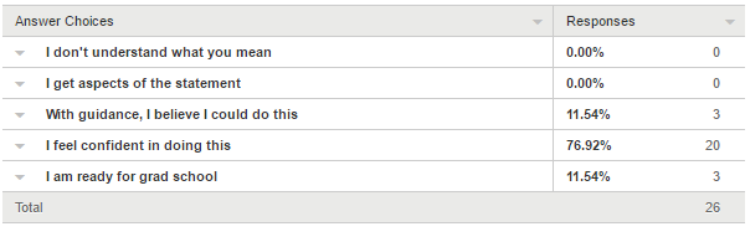

The next question asks, relative to the two traditional lectures that were delivered, whether they perceive that the flipped classroom helps them to learn. The perceived results in Table 8 indicate that the students feel that they learn better in a flipped classroom environment.

\section{Table 8}

\begin{tabular}{l|lr}
\hline Answer Choices & Responses \\
\hline Significantly worse & $3.85 \%$ & 1 \\
\hline Worse & $11.54 \%$ & 3 \\
\hline About the same & $15.38 \%$ & 4 \\
\hline Better & $46.15 \%$ & 12 \\
\hline Significantly better & $23.08 \%$ & 6 \\
\hline Total & & 26 \\
\hline
\end{tabular}


The students are asked whether they feel that flipped classrooms are more engaging than traditional classroom delivery, based on the two traditional lectures given. Table 9 indicates more of a spread of opinion although there is generally agreement that the flipped lectures are more engaging.

\section{Table 9}

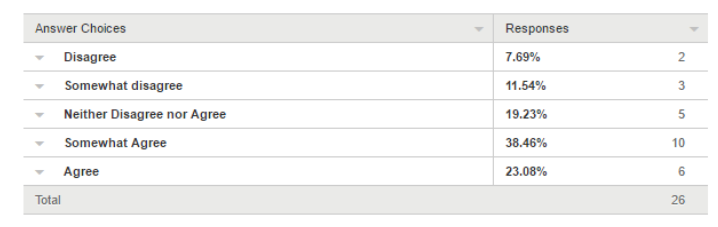

This spread of opinion is also seen when the students are asked whether they would recommend a flipped classroom to their friends. The opinions are split down the middle, as shown in Table 10. In other words, even though the capstone design project show deeper learning, they still would not necessarily recommend this pedagogy to their friends.

\section{Table 10}

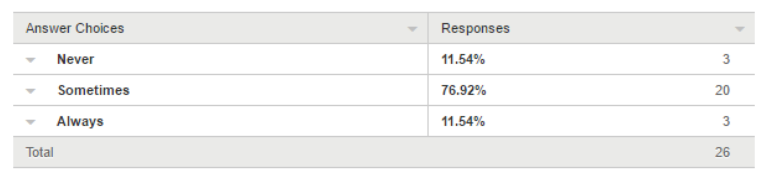

Finally, the students are asked for their perception as to whether the feedback and help from the professors and the Teaching Assistants are better with a flipped classroom. As expected, Table 11 indicates that the students feel that the flipped format give better feedback.

\section{Table 11}

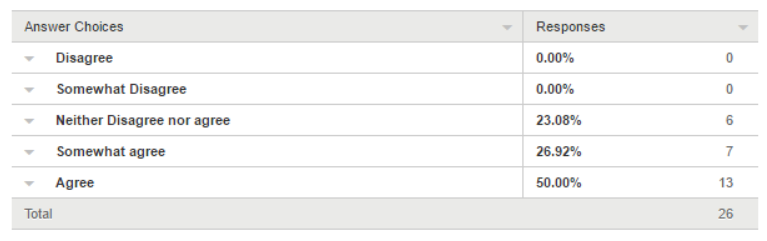

\section{WORKLOAD IMPLICATIONS FOR INSTRUCTOR}

A concern often expressed by instructors who are considering a flipped classroom is the additional workload in preparing the content. The instructor's time in this flipped offering was equally divided between preparing online lectures ( 2 hours for every hour of material) and classroom activities (creating two levels of activities).
Although this is heavier than for a traditional course delivery, it was not onerous.

One reason for the reasonable workload is that the online videos were made based on a normal lecture delivery (i.e. partially completed overheads with the details filled in during the online lecture). Many videos that are made by instructors are overly "flashy", with the misconception that this would increase student engagement. The results of the surveys indicate that the very plain online presentation with the requirements that the students fill in their pdf notes was sufficiently engaging for the students.

\section{CONCLUSIONS}

Overall, the flipped classroom, in particular with the enhancements, results in increased attendance and increased perceived engagement. The capstone project confirms previous research in flipped classrooms that indicate that deeper learning occurs with this pedagogy. It is also demonstrated that the students' ability to use the MATLAB software and their understanding of the threshold concepts of linearization is perceived as being very strong. As expected, the surveys also confirm that feedback to the students was strong.

It is also observed from the instructor's point of view that the assessment of student abilities is much improved. There is no increase in workload in comparison to the student's other courses. Despite a longer length of videos than is recommended in the literature, the strategy of forcing the students to write while they watch appears to result in their perception that the length and engagement of the videos is good. The use of piazza.com also helps give immediate feedback to the students.

There are some concerns that were illustrated over the term. First, the students do not read as much and do not use a textbook. As well, the requirement that all the exercises be done in class means that the student doesn't always encounter material that is highly challenging and is not assessed on difficult content. This tradeoff is offset by the potential that the students learn the material more deeply and it is believed that they will remember the concepts over a longer term. It is difficult to assess the students with a traditional exam and a computer lab exam is implemented instead. Finally, the actual classroom structure (flat floor with fixed tables and chairs) is satisfactory for a flipped classroom but would benefit from a more flexible format with moveable chairs and tables. As flipped classes become more common, it is expected that more suitable spaces need to become available to instructors.

\section{Acknowledgements}

The authors would like to acknowledge the contributions of Philip McCarthy and Keegan Fernandez, 
who acted as excellent Teaching Assistants through this course.

\section{References}

[1] Bishop, Jacob Lowell, and Matthew A. Verleger. "The flipped classroom: A survey of the research," ASEE National Conference Proceedings, Atlanta, GA. vol. 30. no. 9. 2013.

[2] Herreid, Clyde Freeman, and Nancy A. Schiller. "Case studies and the flipped classroom," Journal of College Science Teaching, vol. 42, no. 5, pp. 62-66, 2013.
[3] Mason, Gregory S., Teodora Rutar Shuman, and Kathleen E. Cook. "Comparing the effectiveness of an inverted classroom to a traditional classroom in an upper-division engineering course," IEEE Transactions on Education, vol. 56, no. 4, pp. 430-435, 2013).

[4] Mueller, Pam A., and Daniel M. Oppenheimer. "The pen is mightier than the keyboard advantages of longhand over laptop note taking," Psychological science, 2014.

[5] Zappe, Sarah, et al. "Flipping" the classroom to explore active learning in a large undergraduate course," American Society for Engineering Education, 2009. 